Correspondence concerning this article should be addressed to Aleksandra Kaurin,

Department of Psychology, Witten/Herdecke University, Alfred-Herrhausen-Straße 44, 58455

\section{Attachment Manifestations in Daily Interpersonal Interactions}

\author{
Aleksandra Kaurin ${ }^{\mathrm{a}}$, Paul A. Pilkonis ${ }^{\mathrm{b}}$, \& Aidan G.C. Wright ${ }^{\mathrm{c}}$
}

${ }^{a}$ Faculty of Health/School of Psychology and Psychiatry, Witten/Herdecke University

${ }^{b}$ Department of Psychiatry, University of Pittsburgh School of Medicine

${ }^{c}$ Department of Psychology, University of Pittsburgh 


\begin{abstract}
The predominant focus in attachment research on trait-like individual differences has overshadowed investigation of the ways in which working models of attachment represent dynamic, interpersonally responsive socio-affective systems. Intensive longitudinal designs extend previous work by evaluating to what extent attachment varies over social interactions and the functional processes that underlie its fluctuation. We examined momentary activation of attachment orientations in the stream of peoples' daily lives and how those patterns were linked to interpersonal behavior. Based on an event-contingent, ambulatory 7-day assessment protocol ( $N=263 ; 3971$ interactions) operationalized using Contemporary Integrative Interpersonal Theory, we examined whether contextually activated working models accounted for patterns of interpersonal (anti-)complementarity. Our analyses revealed that the situational activation of working models varied as a function of interpersonal perceptions of warmth, which were linked to greater state security and lower levels of anxious or avoidant expectations. These reactivity patterns, in turn, accounted for interpersonal complementarity. Avoidant attachment was linked to diminished and secure attachment to enhanced expressions of warmth. The analyses were robust even when controlling for momentary positive and negative affect and closeness of the relationship. Attachment expectations wax and wane across daily social interactions, and such fluctuations are reflective primarily of a process in which perceptions of others' warmth activate secure attachment expectations and lower insecure ones.
\end{abstract}

Keywords: attachment; ambulatory assessment; multilevel structural equation modelling; interpersonal theory; working models 
Attachment Manifestations in Daily Interpersonal Interactions

Attachment orientations represent dynamic, socio-affective systems that are activated in actual or imagined interpersonal interactions and reflect an individual's expectations of how others will perceive and behave toward them (Bowlby, 1969, 1980; see also Fraley \& Brumbaugh, 2004). The contextually responsive quality of attachment expectations or internal working models (Mikulincer \& Shaver, 2003), however, has not been assessed within the stream of meaningful everyday social interactions. Instead, research has conventionally operationalized attachment as an individual difference, presumed to generalize over interpersonal situations (Gillath et al., 2009). Thus, what cannot be ascertained from previous studies is how attachment expectations manifest in interpersonal interactions in peoples' daily lives. Consequently, we know little about the functional role of momentary attachment manifestations for daily interpersonal processes. The current study sought to fill this gap. It provides a methodological articulation of attachment that aligns with concepts of working models as contextualized, interpersonally responsive dynamic systems via a 7-day eventcontingent ambulatory assessment protocol.

Attachment theory provides an explanatory framework for understanding the ways in which people initiate and maintain social relationships (Bowlby, 1969; Collins \& Allard, 2001). Traditionally, individual differences in attachment have been structured along two dimensions, anxiety and avoidance (Brennan et al., 1998; Crowell et al., 1999), with securely attached individuals presumably low in both. Conceptually, each of the two attachment dimensions is related to a distinct set of socio-affective processes reflecting beliefs about the availability, trustworthiness, and supportiveness of others along with characteristic patterns of interpersonal perceptions, behaviors, and affect-regulatory strategies (Brennan et al., 1998). In interpersonally threatening or stressful situations, anxious individuals tend to engage in hyperactivating strategies such as hypervigilance and pressured attempts at approach and attachment, whereas avoidant individuals tend to engage in deactivating strategies such as 
keeping others at a distance (Davila \& Kashy, 2009; Mikulincer \& Shaver, 2003). In times of distress, securely attached individuals tend to seek interpersonal comfort and support in more adaptive ways (Bowlby, 1988; Bretherton \& Munholland, 2008).

Adult attachment is assumed to originate from early caregiving experiences and is often conceptualized in terms of stable individual differences (Gillath et al., 2009). However, contemporary theoretical approaches challenge this assumption, proposing instead that adult attachment styles are also shaped by recent interpersonal experiences in a continuously updating process throughout development (Fraley \& Roisman, 2019). This perspective suggests that attachment is a dynamic system that not only influences relationships and interactions but is influenced by them as individuals go about their daily lives.

From the outset, working models of attachment have been defined as flexible relational schemas, likely to be displayed in heterogeneous ways across diverse everyday relational contexts (Bowlby, 1969). Such plasticity results from working models that represent an ensemble of both activating and deactivating behaviors, structured in ways that facilitate one's preferred balance of attachment and autonomy (Mikulincer \& Shaver, 2003). In the past, monthly or yearly fluctuations in attachment have been linked to declines in relationship satisfaction, increases in relationship distress (Girme et al., 2018), and personality pathology (Davila et al., 1997). People, however, hold a variety of working models to accommodate multiple attachment figures and can access contextually relevant guidance for different attachment needs that arise across time (Baldwin \& Fehr, 1995; see also Doherty \& Feeney, 2004; Fraley et al., 2011; Girme \& Overall, 2021; Overall et al., 2003).

Investigating this systematic variation in ways that map onto the dynamic and interpersonal nature of attachment is important because what may appear to be discontinuity over time may not be reflective of general patterns of change per se but a situation-specific manifestation of working models (e.g., Baldwin et al., 1996; Fraley \& Roisman, 2018). In therapy, such situation-specific activation can be used to facilitate change (Levy et al., 2018; 
100 Tasca \& Balfour, 2014) through the provision of context-specific interpersonal experiences

101 (Mallinckrodt, 2010).

Some studies have experimentally examined such patterns of within-person

103 fluctuations of attachment in the context of stressful interpersonal experiences. Having

104 participants recall an occasion during which they felt unloved or disrespected by an

105 attachment figure, as well as experimentally induced relational distress with a key attachment

106 figure, have been associated with temporary decreases in attachment security (Bosmans et al.,

107 2014a; Bosmans et al., 2014b; Vandevivere et al., 2018; Verhees et al., 2020). Similarly,

108 asking participants to imagine someone very supportive in their lives reduced the vividness

109 and distress related to intrusive memories, especially so in participants characterized by less

110 avoidant attachment (Bryant \& Datta, 2019). Such results on the effects of attachment

111 activation were extended by Schreiber et al. (2021), who examined associations between

112 moment-to-moment attachment dynamics and patterns of physiological coregulation in an

113 observational study. In their study, increases in state attachment avoidance were associated

114 with a desynchronization of partners' heart rates, whereas increases in state attachment

115 anxiety were associated with synchronization during a laboratory discussion task.

116 Laboratory observation provides a valuable vantage point, but it tells us little about

117 how attachment expectations influence interpersonal processes in daily life. Thus far, only a

118 few studies have examined the variable impact of attachment expectations in people's daily

119 lives. Over the course of eight weeks, Davila and Sargent (2009) observed that on days when

120 people perceived significant attachment figures to be unavailable, they also tended to

121 experience more attachment insecurity. Similarly, based on a shorter, one-week protocol of

122 daily assessments, Haak et al. (2017) found that on days when participants felt more accepted

123 by their romantic partners, they reported lower levels of anxiety and avoidance. In addition,

124 perceptions of acceptance predicted the next day's attachment security, which was accounted

125 for by lowered negative affect. Finally, an analysis of attachment states and relationship 
126 functioning collected twice a week for four weeks found that daily experiences of lacking

127 emotional support, trust, closeness, affection, friendship, or companionship were associated

128 with attachment anxiety, but not avoidance (Zhang, 2009).

Although it appears that attachment expectations fluctuate in systematic ways across

130 everyday social experiences, previous work did not link the activation of working models to

131 specific interpersonal interactions as they unfold in real-world contexts. To address this gap in

132 the empirical literature, we applied Contemporary Integrative Interpersonal Theory (CIIT;

133 Hopwood et al., 2021; Wright et al., 2020) as a translational framework to address some of

134 the challenges described here and assess attachment processes as they unfold in the daily

135 social lives of individuals. As an integrative model, CIIT encompasses the mental

136 representations central to attachment theory such as the perceived availability or

137 supportiveness of others (in terms of affiliation or dominance) and how that perception is tied

138 to one's own interpersonal behavioral response. More specifically, CIIT rests on the

139 assumption that individual differences (such as those in attachment orientations) emerge from

140 generalized patterns of mental construal (i.e., the way in which we perceive social cues) and

141 from our responses to the proximal behavior of others (Kiesler, 1996; Wright et al., 2017).

142 Previous work (Leary, 1957; Wiggins, 1991) has established two independent

143 dimensions - agency and communion - organizing interpersonal perceptions and behavior.

144 Together they define the interpersonal circumplex, which encompasses attributes of agency

145 and communion. Agency refers to tendencies to be in control vs. tendencies to be passive and

146 seek guidance from others (i.e., dominance vs. submissiveness). Communion refers to

147 tendencies to seek proximity to others vs. tendencies to be distant and socially

148 unapproachable (i.e., affiliation vs. quarrelsomeness). The circumplex structure serves the

149 purpose of identifying how different patterns of interpersonal behavior relate to each other

150 (Zimmermann \& Wright, 2017) and can be used to empirically distinguish behavioral

151 signatures of mental representations such as those related to attachment states in terms of their 
152 prominent interpersonal themes (e.g., Kaurin et al., 2021; Sadikaj et al., 2011). One of the 153 pillars of CIIT is the principle of complementarity (Wiggins, 1991; Wright et al., 2020). It

154 contends that each interpersonal behavior has a counterpart characterized by a similar amount 155 of communion and an opposite amount of agency. To illustrate, dominant behavior tends to 156 elicit or invite submissive behavior, whereas warm behavior tends to elicit or invite warm 157 behavior (Carson, 1969). Interactions in which opposite behavioral patterns emerge (e.g., 158 perceived warmth elicits less of one's own warmth; perceived dominance is met with one's 159 own dominance) are referred to as anti-complementary (Kiesler, 1983). Interactions marked 160 by anti-complementarity are hypothesized to be experienced as aversive, whereas those 161 characterized by at least a moderate amount of complementarity are generally perceived as 162 pleasant (Carson, 1969). These principles can be elaborated and combined with key components of other psychological domains within interpersonal situations such as attachment fluctuations. They have also been used to describe characteristic interpersonal transaction cycles in the context of individual differences such as in personality (Fournier et al., 2009), psychopathology (Benjamin, 1996; Hopwood, 2018), or dispositional attachment

167 orientations (Kaurin et al., 2020a; Sadikaj et al., 2011). Thus, while examining dynamic within-person sequences of interpersonal experience, we used CIIT as a framework to operationalize patterns associated with situationally fluctuating attachment states.

The Current Study. The purpose of this study was to provide a methodological

171 articulation of attachment that aligns with a conceptualization of working models as dynamic 172 systems of interpersonal expectations (Bowlby, 1969; Mikulincer \& Shaver, 2003). To this

173 end, we assessed the interpersonal context (as conceptualized in CIIT) that characterizes the variation of attachment experiences in everyday interpersonal interactions based on a 7-day event-contingent ecological momentary assessment (EMA) protocol. We used CIIT, because

176 it provides a set of concepts to empirically test specific instantiations of mental

177 representations in social interactions in daily life. Effects of individual differences in 
178 attachment orientations were distinguished from effects at the level of social interactions via multilevel structural equation modelling (MSEM). In line with CIIT, we evaluated whether and to what extent perceptual and behavioral features of interpersonal interactions were linked to attachment expectations in daily life. Consistent with CIIT's focus, we sampled perceptions and behaviors using the dimensions of dominance and warmth. We then examined within-

183 person models to test whether attachment states that varied across situations were linked to differential affective and interpersonal responses. More specifically, to provide insight into social situations characteristic of insecure attachment, we examined whether reactive changes in attachment accounted for interpersonal (anti-)complementarity via two critical pathways:

187 The momentary elevation of state attachment in response to perceptions of one' interaction

188 partner (attachment activation) and the unfolding interpersonal behavioral response (attachment manifestation; see Figure 1).

We hypothesized that situational fluctuations of attachment would be associated with the perceived nature of the interaction (i.e., dominance, warmth) such that they would reflect characteristic patterns of interpersonal perceptions, behaviors, and regulatory strategies (Brennan et al., 1998). Our prediction is based on previous work proposing that patterns of interpersonal perceptions and behaviors vary as a function of attachment orientations (e.g., Fraley \& Brumbaugh, 2004; Kaurin et al., 2020a). It is also informed by work suggesting that in interpersonally stressful situations, anxious individuals tend to engage in pressured

197 attempts at approach, avoidant individuals tend to keep others at a distance (Davila \& Kashy, 198 2009; Mikulincer \& Shaver, 2003), and securely attached individuals tend to seek

199 interpersonal comfort and support in more adaptive ways (Bowlby, 1988; Bretherton \& 200 Munholland, 2008). Specifically, we hypothesized that when interactions were characterized 201 by a strong availability and supportiveness of an interaction partner via perceived 202 interpersonal warmth, higher security and lower anxiety and avoidance would be observed.

203 Conversely, in interactions characterized by a lack of availability and supportiveness such as 
via perceived interpersonal dominance, lower security and higher anxiety and avoidance would be observed. Because of these relationships, we further hypothesized that avoidant attachment states would covary with dominant, interpersonally cold and distant behavior, whereas anxious attachment states would more likely be linked to submissiveness and proximity-seeking, as an indicator of characteristic hyperactivation strategies. Secure attachment states, in turn, would be characterized by warm and affiliative interpersonal behavior.
Method

All study procedures were approved by the Institutional Review Boards of the University of Pittsburgh (IRB Protocol \#: STUDY20090074). This study was not preregistered and all data have been made publicly available at the OSF and can be accessed at https://osf.io/3vy4m/. We report how we determined our sample size, all data exclusions, and all measures in the study.

\section{Sample}

Undergraduate students $(N=263 \text {, reporting } 3971 \text { social interactions })^{1}$ were recruited online from introductory psychology courses at the University of Pittsburgh. Participants were $\sim 57 \%$ female and ranged in age from 18 to 27 , with the majority (87.3\%) being 18 and 19 years old $(M=18.81, S D=1.98)$. Most participants identified as white $(66.53 \%, n=175)$, $17.87 \%$ as Asian $(n=47), 7.22 \%$ as black $(n=19)$ and the remainder as other. Participants received course credit for completing the baseline questionnaires and EMA protocol. Full credit was awarded to individuals who completed an average of four or more surveys per day. This number is based on extensive prior use of these methods. It reflects the average amount

\footnotetext{
${ }^{1}$ For reasons of inter-study consistency and reliability, we usually exclude participants with low numbers of reported interactions $(\leq 10)$ when estimating multilevel structural equation models. Because our analyses mainly focused on the within-person portion of the models, the results did not differ as a function of reported interactions per participant. Thus, at the request of an anonymous reviewer, we decided to deviate from this practice. Accordingly, results based on the subset with a minimum of 10 interactions per participant were moved to online supplementary materials at https://osf.io/3vy4m/ (i.e., syntax, output, APA formatted tables).
} 
that people have reported in earlier studies and matches a cutoffs of $\sim 70 \%$ of surveys

completed used in related studies (e.g., Kaurin et al., 2020b).

\section{Sample Size Justification}

Two aspects guided our selection of the target sample size: First, our dataset was intended to serve as resource that can be examined to answer many questions expected to range in effect size. We anticipated that most analyses would be based on covariance matrices like those described in the present paper. Therefore, the choice of our target sample size was most strongly influenced by our appeal to derive stable effect estimates, in contrast to having the power to detect any specific effect size in the population. Recent work has suggested that correlation estimates consistent with the average effect in the literature on individual differences begin to stabilize when sample sizes approach $N=250$ (Schönbrodt \& Perugini, 2013). Thus, for our most conservative tests, which would be between-person associations given the hierarchical structure of the data (interactions nested within persons), we sought a minimum sample size of $N=250$. The within-person portions of the models would be expected to far exceed this number given each participant reported on multiple interactions.

\section{Procedure}

Participants viewed a video-assisted training presentation explaining the EMA procedures and instructions for downloading the MetricWire smartphone application (MetricWire, Inc., 2019) as part of an online study orientation. To ensure that all participants understood and followed the instructions, a brief comprehension quiz was administered after the orientation. Respondents were not allowed to participate until they passed the quiz. Participants completed a seven-day ${ }^{2}$ event-contingent ambulatory assessment protocol and were asked to fill out a survey following any interpersonal interaction that lasted at least 5 minutes. In addition to situational attachment expectations, participants reported on

\footnotetext{
${ }^{2}$ Although the protocol was designed for a period 7 days, the number of days in the study varied across participants. Some participants provided more than 7 days of assessments because the last data download for them did not transpire exactly on day 7 of the study.
} 
perceptions of their interaction partner's behavior and their own interpersonal behavior and affective experience during interactions (Kaurin et al., 2020a, 2020b; Wright et al., 2017).

Reports of $N=3971$ interactions, based on $N=263$ participants, were collected with an average of $10.5(S D=7.27)$ interactions per participant. The average number of surveys completed across participants with a minimum of 10 interactions $(N=3574)$ was $19.53(S D=6.30)$.

State Attachment. We used nine items to assess momentary attachment expectations derived from the State Adult Attachment Measure (SAAM; Gillath et al., 2009). Based on 257 face validity and the factor loadings and results reported in Gillath et al. (2009), we selected 258 items that were most indicative of each attachment dimension and were likely to be 259 responsive to interpersonal interactions. Reliability for included scales was demonstrated with 260 McDonald's omega values ( $\omega$; Zinbarg et al., 2005), calculated using the psych (Revelle, 2020) package in R. Each of the chosen SAAM items was re-worded to be reflective of 262 feelings in a given interpersonal situation. For example, we re-phrased "I feel alone and yet 263 don't feel like getting close to others" to "I felt alone and yet didn't feel like getting close to 264 the other person." Participants were asked to indicate how they felt during the interaction on a 265 seven-point scale ( $0=$ "disagree strongly" to $4=$ "agree strongly"). To be consistent with the

266 scoring of the original scale, we created mean scores of items reflecting anxious $\left(\omega_{\text {within }}=.86\right.$;

$\left.267 \omega_{\text {between }}=.89\right)$, avoidant $\left(\omega_{\text {within }}=.71 ; \omega_{\text {between }}=.90\right)$ and secure $\left(\omega_{\text {within }}=.69 ; \omega_{\text {between }}=.92\right)$

268 attachment orientations. The full set of SAAM items used in this study can be found via 269 https://osf.io/3vy4m/.

270 Affect. At each assessment, participants rated the degree to which they felt positive 271 (i.e., happy, excited) and negative emotions (i.e., ashamed, nervous, hostile, sad, and angry) 272 derived from the Positive and Negative Affect Schedule (Watson et al., 1988). Positively and 273 negatively valenced items were separately averaged to create an overall negative or positive 274 affect scale. Items read "How [ADJECTIVE] did you feel during the interaction?", and 
ratings were made on a slider scale from 0 ("Not at All") to 100 ("Extremely") for each

adjective (positive: $\omega_{\text {within }}=.75 ; \omega_{\text {between }}=.91$; negative: $\omega_{\text {within }}=.71 ; \omega_{\text {between }}=.89$ ).

Interpersonal Behavior. When participants indicated that an interpersonal interaction

had occurred, they reported on their own behavior and the behavior of the person with whom

they interacted. The item prompts were: "Please rate how the OTHER PERSON BEHAVED toward you during the interaction" and "Please rate YOUR BEHAVIOR toward the other person during the interaction." For both self and other, dominance was rated from

“Accommodating/Submissive/Timid" to "Assertive/Dominant/Controlling" and warmth was rated from "Cold/Distant/Hostile" to "Warm/ Friendly/Caring" on 101-point slider scales (-50 to +50 ). These items were developed to reflect daily behavioral manifestations of affiliative and agentic motives described by interpersonal theory (Kiesler, 1996; Wiggins, 1991) and have demonstrated good construct validity in several samples (Woods et al., 2020). participants were also asked to describe some aspects of their interactions in detail. They were asked to indicate the interaction partner's relationship to them, how frequently they interacted with the person, as well as to specify the kind of interaction they were having. In most instances, interaction partners were described as friends $(47.18 \%)$, followed by a family member including parents (23.97\%), significant others or casual romantic partners $(10.27 \%)$, acquaintances $(5.69 \%)$ or work or school related encounters $(6.99 \%)$. The remainder were

294 either persons that have not been met before (4.31\%) or responses classified as "other" 295 (1.5\%). In general, interaction partners were persons with whom our participants were in touch on a daily basis $(47.67 \%)$, or at least 2-6 days a week $(29.45 \%) . \sim 11 \%$ reported being in touch with their interaction partners once a week and roughly $\sim 11 \% 1-11$ times a year. Most interactions took place in person $(56.88 \%), 11.53 \%$ were phone calls, $15.03 \%$ text chats, $16.39 \%$ video calls, and $0.18 \%$ described as other. To statistically control for the salience of the interaction and relevance of the partners for one's attachment system, we also asked 
participants to describe the closeness of the relationship within which the interaction was unfolding ("How close are you to the person you interacted with?"; 0 - "Not at all close" to 100 - "Extremely Close"). The mean value of this rating $(M=67.43 ; S D=30.42)$ aligns with categorical data above, indicating that, on average, participants were interacting with close 305 others.

\section{Data Analysis}

307 To capture dynamic processes in the context of daily interpersonal interactions, we 308 used multi-level structural equation models (MSEM; Sadikaj et al., 2021). Assessing 309 attachment states across interpersonal interactions in daily life geneartes a hierarchical data 310 structure, wherein social interactions are nested within individuals. MSEM allows the

311 variability in individuals' responses to be partitioned into between- and within-person 312 components. Between-person variance reflects individual differences in average responses, 313 and the corresponding portion of the model estimates associations among individual

314 differences in each observed variable, akin to coefficients derived from cross-sectional 315 designs. In contrast, within-person variance reflects interaction-to-interaction fluctuations 316 around an individual's average level, helping to determine whether specific relational events 317 lead to contextual (as opposed to enduring) changes in working models.

318 This variance decomposition approach allows us to assess trait-like and contextual 319 interpretations of working models of attachment, without putting them into opposition. That 320 is, although it is likely that there is significant within-person variation in attachment patterns, 321 that variation is best understood as a contextual deviation from a person's typical attachment 322 orientation (Sadikaj et al., 2021). Thus, the outcomes key to these analyses - i.e., the dynamic responses of one's attachment system - are reflected in within-person results. These results

324 allow us to articulate quantitatively how and to what extent attachment expectations fluctuate 325 across daily interactions and how much a person's own warm or dominant behavior covaries 326 with such fluctuations. All within-person regression paths were estimated as random slopes, 
which allows us to test how much individuals differ in the strength and direction of their within-person associations. The fixed effects of these slopes represent the average association in the sample, and the random effects represent individual differences in the extent to which situational features influence participants.

Figure 1 provides a diagram of the focal model including an overview of momentary within-person links. We regressed ratings of momentary attachment experiences on perceptions of the other's behavior during an interpersonal situation, a path we refer to as attachment activation. In our model, attachment expectations were situated as an intervening variable to account for the associations between perceptions of others' and one's own behavior. In line with CIIT, we refer to the path between perception of other's and one's own behavior as interpersonal complementarity. The link between attachment expectations and one's own behavior is labeled attachment manifestation. At the between-person level, we estimated associations between average individual differences in perceptions of others, attachment expectations, and one's own behavior. Because all variables were measured contemporaneously and it is assumed that they are mutually influential within interpersonal interactions, our study goal was not to model causality or the temporal ordering of the variables. Instead, the paths included in the models reflect this study's emphasis on evaluating the unique effects of attachment on interpersonal behavior.

In subsequent sensitivity analyses, we examined further the specific effects of attachment expectations by parsing out variance attributable to other theoretically relevant constructs. To this end, we controlled for (negative and positive) affect (see grey paths in Figure 1), given the close relationship between attachment and affect-regulatory processes (Davila \& Sargent, 2009). Because attachment-related dynamics may be influenced by longitudinal aspects of a relationship (Cook, 2000; La Guardia et al., 2000; Pierce \& Lydon, 2001), we also accounted for the closeness of the relationship, at both levels of analysis. 
352 These sensitivity analyses are summarized in Tables 3 (negative affect), 4 (positive affect) 353 and 5 (closeness). parameters not reported in the tables (e.g., residual variances), covariances among betweenpersons variables are not depicted in the diagrams, but full specifications and detailed output from all models can be found online at https://osf.io/3vy4m/. Table 1 summarizes pooled within-person correlations among the variables and correlations among the random intercepts at the between-person level. data were assumed to be missing at random. A Bayesian approach to SEM uses all available data in estimation which - with increasingly large samples - provides results comparable to those achieved with Full Information Maximum Likelihood to address missing data (Asparouhov \& Muthén, 2010). Significance for all model parameters was based on 95\% Credibility Intervals (CIs), with CIs that excluded zero indicating a parameter that differed significantly from zero. Sex $(0=$ female; $1=$ male $)$ and age (centered on mean age) were included as covariates in all models at the between-person level, and interaction number (i.e., daily number of interactions centered on mean number of observations per day) was entered as a within-person covariate.

\section{Results}

Descriptive statistics and bivariate correlations are summarized in Table 1. Intraclass correlations (ICCs) are also presented in Table 1 indicating the proportion of between-person variance in each observed variable. Subtracting the ICC from 1.0 provides the within-person variance and indicates the proportion of state variance of a given construct. Overall, attachment expectations were characterized by differing levels of between-person and withinperson variance. Descriptively, the lowest levels of stability emerged for secure attachment $(\mathrm{ICC}=.17)$, followed by avoidant $(\mathrm{ICC}=.31)$ and anxious $(\mathrm{ICC}=.43)$ attachment. To 
contextualize, ICCs for attachment were within the range of values established for negative

$(\mathrm{ICC}=.34)$ and positive affect $(\mathrm{ICC}=.20)$ and interpersonal perceptions $\left(\mathrm{ICC}_{\text {warmth }}=.18\right.$;

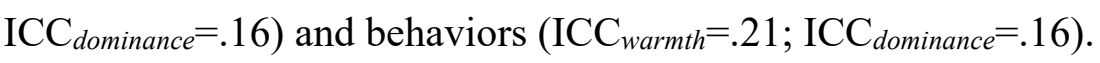

Focal Model. In the models central to this paper, we tested whether the link between

382 perceptions of others' and one's own behavior was accounted for by state attachment

383 expectations. The results of this model are presented in Table 2. For models examining the

384 effects of others' perceived warmth on one's own warm behavior, we found significant fixed effects at the within-person level (interpersonal complementarity), as well as the betweenperson level $\left(\right.$ Beh $_{i} \rightarrow$ Perc $\left._{i}\right)$. Perceiving others as more affiliative was associated with higher levels of attachment anxiety and security, and lower levels of avoidant attachment (attachment activation within-person path). The effect sizes for anxiety and security differed markedly, with the effect for security approximately 4 times that of anxiety. At the same time, avoidant attachment expectations were associated with less, while secure attachment expectations were associated with more interpersonally warm behaviors (attachment manifestation within-person path), over and above the effect of perceived warmth. of these same interpersonal processes. Perceiving interaction partners as more dominant was associated with less of one's own dominant behavior at the within-person, but more dominant behavior at the between-person level. Thus, in the moment, when participants were perceiving someone as more dominant, they tended to behave in more submissive ways. However, those who generally perceived others as dominant, also tended to behave in more dominant ways, a general pattern indicative of anti-complementarity. agentically. Perceptions of others as dominant were associated with higher levels of attachment security and avoidance (attachment activation within-person path). At the same 
time, secure attachment expectations were related to less interpersonally dominant behaviors (attachment manifestation within-person path), over and above the effect of perceived dominance; avoidant attachment expectations were not related to dominant behavior. Momentary activation patterns of anxious attachment, however, were neither related to 408 perceptions of others as dominant, nor one's own dominant behavior.

Sensitivity Analysis. To check whether the observed effects were robust to the influence of alternative, theoretically plausible variables, we examined the extent to which

411 they were affected by the simultaneous introduction of negative or positive affect or

412 closeness. For this purpose, we included affect and self-reported closeness in separate models 413 as parallel intermediate variables in the interpersonal complementarity path (see grey model 414 parts in Figure 1). The respective coefficients can be retrieved from Tables 3-5. As evident, the overall pattern of results did not change. One exception was that the link between avoidant attachment states and perceived dominance disappeared when controlling for negative affect. At the same time, a small suppression effect emerged, in that a significantly positive link between avoidant attachment states and own dominance appeared

419 when we controlled for positive affect and closeness of the relationship. Moreover, the 420 anxious attachment manifestation path in interactions perceived as warm was larger when we 421 controlled for affect. Positive and negative affect were generally associated in expected

422 directions with attachment, such that momentary elevations of avoidant and anxious 423 attachment were linked to more negative and less positive affect, whereas the reverse was true 424 for momentary elevations of secure attachment. Two exceptions from this overall pattern 425 were that at the between-person level no significant link between positive affect and anxious 426 or avoidant attachment emerged. In line with previous work (Kaurin et al., 2020; Wright et 427 al., 2017), negative and positive affect were associated in expected directions with affiliation 428 and dominance. 
The second robustness check examined the impact of closeness of the relationship within which the interaction was unfolding. Again, the pattern of results observed in Table 3 did not change, and closeness was related to attachment and interpersonal perceptions as well as behavior in theoretically plausible directions.

\section{Discussion}

Attachment refers to the ways in which people manifest their need for relatedness and proximity to others, especially in times of need/distress. In this study, we harnessed the potential of intensive longitudinal data to test the assertion that working models of attachment represent adaptive socio-affective systems, reflected in fluctuations across daily social interactions. Overall, we found that the situational activation of working models varied as a

439 function of interpersonal perceptions, and that these patterns accounted, in part, for 440 interpersonal complementarity in interactions that were perceived as warm and when people were expressing warmth in response. Our findings demonstrate that situational attachment variability represents an adaptive process, which coordinates regulation of interpersonal responses. This is important because our findings suggest that greater within-person

444 fluctuation in situational attachment may not necessarily reflect inconsistent evaluations of 445 others, which is often discussed in the context of personality pathology (e.g., Davila, Burge, \& Hammen, 1997). Rather, distinctive experiences in close relationships activate different attachment expectations, thus setting adaptive processes of interpersonal responding in motion. The results help to characterize the interpersonal context within which intra-

449 individual variation in attachment expectations occur. This perspective serves to balance the 450 focus on how generalized patterns of attachment influence social behavior, which tends to 451 inform much prior research (Smith, Msetfi, \& Golding, 2010; Kaurin et al., 2020). More specifically, in this study, interactions characterized by warmth typically cooccurred with elevated levels of attachment security and lowered levels of attachment anxiety 454 or avoidance, but only states of security and avoidance tended to co-occur with one's own 
expressed warmth. The absence of a relationship between warmth and anxious attachment

may imply that sometimes attachment anxiety is expressed in more warm behavior and sometimes in less. attachment. At the same time, secure attachment manifestations were linked to less of one's own dominant behavior. Generally, this pattern aligns with previous work suggesting that the formation of stable romantic relationships is linked to enhanced attachment security and decreased attachment insecurity (Feeney \& Noller, 1992; Hammond \& Fletcher, 1991;

464 Kirkpatrick \& Hazan, 1994), that those changes occur in coordinated ways among couples 465 (Hudson et al., 2014), and that attachment dynamics likely act as facilitators of therapeutic change (e.g., Bernecker, Levy, \& Ellison, 2014). At the same time, the present results extend such lines of work by offering a methodology and analyses that illustrate change processes as an ensemble of directed activations of a person's attachment system. manifestation of attachment processes in daily interpersonal interactions. Although EMA

471 provides a unique window into daily attachment processes, there is little empirical evidence on how long those experiences last, when they are resolved, or how they feed back into the development or alteration of more stable traits or symptoms. Thus, a key question arising

474 from our analyses is whether attachment manifestations are a cause, in and of themselves, of 475 interpersonal behaviors or whether they represent a correlate, but not a causal component of 476 interpersonal perceptions and behaviors. Since all variables were measured 477 contemporaneously, we can only conclude that attachment, affect, interpersonal perception, 478 and behavior are reciprocally influential within an interaction. Such limitations remind us that 479 although it is plausible that specific interpersonal interactions set the attachment system in 480 motion, causal inferences, or assumptions about the temporal ordering of the variables should 
481 be made with caution. Instead, the paths included in the models reflect this study's emphasis on evaluating the unique effects of attachment (and affect and the closeness of the relationship) on interpersonal behavior. Now that we have demonstrated that systematic variability within daily attachment states exists, specific situational contexts that may set one's attachment system in motion should be examined. Future work should also strive to

486 better capture the timescale, functional relationships, and causal mechanisms of these 487 processes, and treat the attachment dimensions not as independent but synergistic and study potential interactions among them in predicting interpersonal behavior.

490 patterns of thinking, feeling, and behaving, a high level of stability may be indicative of 491 increased covariation among variables that shape an individual's attachment expectations 492 rather than less responsivity of the attachment system per se (Fraley \& Brumbaugh, 2004).

493 Secure attachment expectations were the most variable, with more than $80 \%$ of their variance 494 explained by situational factors, a pattern that was similar for avoidant attachment (i.e., $70 \%$ 495 within-person variance). In contrast, anxious attachment had more equal portions of between496 and within-person variance (i.e., 59\% state variance), documenting that anxious attachment 497 expectations were characterized by more modest fluctuations around an individual's average 498 level. The high level of within-person variance may also be indicative of an individual's 499 exploratory drive - attachment security allows a person to explore the environment in 500 unhindered fashion (Elliot \& Reis, 2003). This pattern needs to be replicated in future studies, 501 assessing how people gain novel experiential knowledge across situations or relationships 502 within which change is likely to occur. Moreover, such work could also provide insight into 503 how both partners' individual differences in attachment may enhance or inhibit each other and 504 how dyadic patterns of momentary activation relate to longer term patterns of change. A series of sensitivity analyses provided evidence for the robustness of the results 506 presented in our main analyses. They indicated that attachment processes in daily life made an 
independent contribution to interpersonal complementarity, over and above potential effects of positive and negative affect and the closeness of the relationship. In line with Davila \& Sargent (2009), within-person links between interpersonal perceptions and attachment

510 expectations remained significant even after accounting for affect in interpersonal situations.

511 This result supports the assumption that attachment expectations reflect processes beyond

512 those shared with general efforts at affect regulation.

513 Because we were unable to directly compare attachment dynamics in interactions

514 involving specific attachment figures (e.g., romantic partner, close friend, parent, sibling), we

515 addressed this limitation by statistically controlling for the closeness of the relationship with

516 daily interaction partners. This analysis did not alter the pattern of results.

517 Our findings underscore the importance of ecologically valid methods for naturalistic

518 characterizations of responsive patterns of intra-individual variation in attachment

519 expectations. Our models were based on the perceptions of the individual as key predictors

520 for two reasons. First, self-reports typically provide a more accurate assessment of processes

521 that are low in observability (such as mental construal; Vazire, 2010). Second, interpersonal

522 theory emphasizes the situation as construed by the individuals participating in it (Kiesler,

523 1996). However, our use of self-report also contributes to shared method variance between

524 momentarily assessed variables. Attachment is often assessed by observation, and future work

525 should use methods that capture more overt features of the situation and attachment

526 manifestations. Perspectives that prioritize objective assessments of the situation (Rauthmann

527 et al., 2015) may help disentangle true differences in the warmth and dominance of

528 interpersonal interactions from perceived warmth and dominance as well as systematic

529 differences in interaction partners that arise in the context of dispositionally insecure

530 attachment. 
One possibility might be to use a yoked ambulatory assessment design, in which one

532 person provides data about an event (e.g., conflict) and another is prompted to do the same (e.g., patient's spouse).

We acknowledge that sampling may also have affected the generalizability of our results. Our data were drawn from a convenience sample (i.e., undergraduates from a large university), and on average, participants reported generally secure attachment experiences. Insecure attachment states, in contrast, were less frequently endorsed, which led to more skewed distributions. Moreover, a large proportion of our sample reported low numbers of interpersonal interactions $(\leq 10)$. Although the general pattern of our results was independent of the number of interactions per participant (see footnote above), future studies should focus on capturing systematic variation in the frequency of interactions in people's daily lives. In our data, the amount of reported social contact was unrelated to anxious $(r=.02, p=.77)$ or avoidant ( $r=-.01, p=.87)$ attachment, nor did we find a statistically significant link to psychopathological dimensions relevant to the quality and frequency of interpersonal interactions such as negative affectivity $(r=.06, p=.37)$, detachment $(r=-.05, p=.46)$, antagonism $(r=-.05, p=.39)$, disinhibition $(r=-.12, p=.06)$ or psychoticism $(r=-11, p=.07)$ as assessed by the Personality Inventory for DSM-5-Brief Form (PID-5; Krueger et al., 2012). Thus, our results should be replicated in clinical samples, especially those where relationship experiences and enhanced affective reactivity play a significant role in the etiology and maintenance of disorders and where there are likely to be higher levels of variability in the traits mentioned above (e.g., Wright et al., 2017).

\section{Conclusion}

Attachment expectations simultaneously arise from and influence the pattern and quality of social interactions in peoples' daily lives. We provide evidence for reactive variation in attachment expectations across social interactions which, in turn, are associated with interpersonal complementarity. Our findings elaborate the conceptualization of working 
557 models of attachment as a mix of not only stable dispositions, but also contextual components

558 related to the flow of daily experience. Building on CIIT, this work sheds light on attachment

559 expectations as a key element linking perceptions of others with one's own behavioral

560 response. This approach allows us to identify dynamic elements of human relatedness, with

561 the hope that deeper understanding of such processes will improve our clinical efforts to

562 enhance interpersonal effectiveness and secure attachment. 


\section{References}

564 Asparouhov, T., \& Muthén, B. (2010). Bayesian analysis using Mplus: Technical implementation (Mplus Technical Report). http://statmodel. com/download/Bayes3.pdf

Baldwin, M. W., \& Fehr, B. (1995). On the instability of attachment style ratings. Personal Relationships, 2(3), 247-261. https://doi.org/10.1111/j.1475-6811.1995.tb00090.x

Baldwin, M. W., Keelan, J. P. R., Fehr, B., Enns, V. \& Koh-Rangarajoo, E. (1996). Socialcognitive conceptualization of attachment working models: Availability and accessibility effects. Journal of Personality and Social Psychology, 71(1), 94-109. https://doi.org/10.1037/0022-3514.71.1.94

Bernecker, S. L., Levy, K. N. \& Ellison, W. D. (2013b). A meta-analysis of the relation between patient adult attachment style and the working alliance. Psychotherapy Research, 24(1), 12-24. https://doi.org/10.1080/10503307.2013.809561

Bosmans, G., Bowles, D. P., Dewitte, M., De Winter, S., \& Braet, C. (2014a). An experimental evaluation of the State Adult Attachment Measure: The influence of attachment primes on the content of state attachment representations. Journal of Experimental Psychopathology, 5(2), 134-150.

Bosmans, G., Van de Walle, M., Goossens, L., \& Ceulemans, E. (2014b). (In) variability of attachment in middle childhood: Secure base script evidence in diary data. Behaviour Change, 31(4), 225-242.

583 Bowlby, J. (1969). Attachment and loss. Vol. I: Attachment. Hogarth Press.

584 Bowlby, J. (1980). Attachment and Loss. Vol. 3: Loss, Sadness and Depression. Basic Books.

585 Brennan, K. A., Clark, C. L., \& Shaver, P. R. (1998). Self-report measurement of adult attachment: An integrative overview. In J. A. Simpson \& W. S. Rholes (Eds.), Attachment theory and close relationships (pp. 46-76). The Guilford Press.

588 Bretherton, I., \& Munholland, K. A. (2008). Internal working models in attachment 

relationships: Elaborating a central construct in attachment theory. In J. Cassidy \& P. R. Shaver (Eds.), Handbook of attachment: Theory, research, and clinical applications (pp. 102-127). The Guilford Press.

592 Bryant, R. A. \& Datta, S. (2019). Reconsolidating Intrusive Distressing Memories by Thinking of Attachment Figures. Clinical Psychological Science, 7(6), 1249-1256. https://doi.org/10.1177/2167702619866387

Carson, R. C. (1969). Interaction Concepts of Personality. Chicago: Aldine.

Collins, N. L. , \& Allard, L. M. (2001). Cognitive representations of attachment: The content and function of working models. In G. J. O. Fletcher \& M. S. Clark (Eds.), Blackwell handbook of social psychology: Vol. 2. Interpersonal processes (pp. 60-85).

600 Blackwell.

Cook, W. L. (2000). Understanding attachment security in family context. Journal of Personality and Social Psychology, 78(2), 285-294. https://doi.org/10.1037/0022-3514.78.2.285

Feeney, J. A. \& Noller, P. (1992). Attachment style and romantic love: Relationship

Crowell, J. A., Fraley, R. C., \& Shaver, P. R. (1999). Measurement of individual differences in adolescent and adult attachment. In J. Cassidy \& P. R. Shaver (Eds.), Handbook of attachment: Theory, research, and clinical applications (pp. 434-465). Guilford Press.

Davila, J., Burge, D. \& Hammen, C. (1997). Why does attachment style change? Journal of Personality and Social Psychology, 73(4), 826-838. https://doi.org/10.1037/0022-3514.73.4.826

612 Davila, J. \& Kashy, D. A. (2009). Secure base processes in couples: Daily associations between support experiences and attachment security. Journal of Family Psychology, 23(1), 76-88. https://doi.org/10.1037/a0014353 
615 Doherty, N. A. \& Feeney, J. A. (2004). The composition of attachment networks throughout

616

617

618

619

620

621

622

623

624

625

626

627

628

629

630

631

632

633

634

635

636

637

638

639 the adult years. Personal Relationships, 11(4), 469-488. https://doi.org/10.1111/j.1475-6811.2004.00093.x

Elliot, A. J. \& Reis, H. T. (2003). Attachment and exploration in adulthood. Journal of Personality and Social Psychology, 85(2), 317-331. https://doi.org/10.1037/0022-3514.85.2.317

Fraley, R. C., \& Brumbaugh, C. C. (2004). A Dynamical Systems Approach to Conceptualizing and Studying Stability and Change in Attachment Security. In W. S. Rholes \& J. A. Simpson (Eds.), Adult attachment: Theory, research, and clinical implications (pp. 86-132). Guilford Publications.

Fraley, R. C., Vicary, A. M., Brumbaugh, C. C., \& Roisman, G. I. (2011). Patterns of stability in adult attachment: An empirical test of two models of continuity and change. Journal of Personality and Social Psychology, 101(5), 974992. https://doi.org/10.1037/a0024150

Fraley, R. C. \& Roisman, G. I. (2019). The development of adult attachment styles: four lessons. Current Opinion in Psychology, 25, 26-30. https://doi.org/10.1016/j.copsyc.2018.02.008

Gillath, O., Hart, J., Noftle, E. E. \& Stockdale, G. D. (2009). Development and validation of a state adult attachment measure (SAAM). Journal of Research in Personality, 43(3), 362-373. https://doi.org/10.1016/j.jrp.2008.12.009

Girme, Y. U., Agnew, C. R., VanderDrift, L. E., Harvey, S. M., Rholes, W. S., \& Simpson, J. A. (2018). The ebbs and flows of attachment: Within-person variation in attachment undermine secure individuals' relationship wellbeing across time. Journal of Personality and Social Psychology, 114(3), 397-421. https://doi.org/10.1037/pspi0000115 
640 Girme, Y. U., \& Overall, N. C. (2021). A Functional Account of Multiple Internal Working Models. Attachment: The Fundamental Questions, 136-143.

642

Haak, E. A., Keller, P. S. \& DeWall, C. N. (2017). Daily variations in attachment anxiety and avoidance: A density distributions approach. Journal of Research in Personality, 69, 218-224. https://doi.org/10.1016/j.jrp.2016.08.002

Hammond, J. R., \& Fletcher, G. J. (1991). Attachment styles and relationship satisfaction in the development of close relationships. New Zealand Journal of Psychology, 20(2), $56-62$.

Himmelstein, P.H., Woods, W.C., \& Wright, A.G.C. (2019). A comparison of signal- and event-contingent ambulatory assessment of interpersonal behavior and affect in social situations. Psychological Assessment, 31(7), 952-960.

Hopwood, C. J., Pincus, A. L. \& Wright, A. G. (2021). Six assumptions of contemporary integrative interpersonal theory of personality and psychopathology. Current Opinion in Psychology, 41, 65-70. https://doi.org/10.1016/j.copsyc.2021.03.007

Hudson, N. W., Fraley, R. C., Brumbaugh, C. C. \& Vicary, A. M. (2014). Coregulation in Romantic Partners' Attachment Styles. Personality and Social Psychology Bulletin, 40(7), 845-857. https://doi.org/10.1177/0146167214528989

Kaurin, A., Beeney, J. E., Stepp, S. D., Scott, L. N., Woods, W. C., Pilkonis, P. A. \& Wright, A. G. (2020a). Attachment and Borderline Personality Disorder: Differential Effects on Situational Socio-Affective Processes. Affective Science, 1(3), 117-127. https://doi.org/10.1007/s42761-020-00017-7

Kaurin, A., Dombrovski, A. Y., Hallquist, M. N. \& Wright, A. G. C. (2020b). Momentary interpersonal processes of suicidal surges in borderline personality disorder. Psychological Medicine, 1-11. https://doi.org/10.1017/s0033291720004791 
664 Kiesler, D. J. (1983). The 1982 Interpersonal Circle: A taxonomy for complementarity in

665

666

667

668

669

670

671

672

673

674

675

676

677

678

679

680

681

682

683

684

685

686

687

688 human transactions. Psychological Review, 90(3), 185214. https://doi.org/10.1037/0033-295X.90.3.185

Kiesler, D.J. (1996). Contemporary interpersonal theory and research: Personality, psychopathology, and psychotherapy. John Wiley \& Sons.

Kirkpatrick, L. A., \& Hazan, C. (1994). Attachment styles and close relationships: A fouryear prospective study. Personal Relationships, 1(2), 123-142. https://doi.org/10.1111/j.1475-6811.1994.tb00058.x

Krueger R, Derringer J, Markon K, Watson D, Skodol A. The personality inventory for DSM5-brief form (PID-5-BF) — adult. Washington, DC: American Psychiatric Association; 2013.

La Guardia, J. G., Ryan, R. M., Couchman, C. E. \& Deci, E. L. (2000). Within-person variation in security of attachment: A self-determination theory perspective on attachment, need fulfillment, and well-being. Journal of Personality and Social Psychology, 79(3), 367-384. https://doi.org/10.1037/0022-3514.79.3.367

Lazarus, S. A., Scott, L. N., Beeney, J. E., Wright, A. G. C., Stepp, S. D., \& Pilkonis, P. A. (2018). Borderline personality disorder symptoms and affective responding to perceptions of rejection and acceptance from romantic versus nonromantic partners. Personality Disorders: Theory, Research, and Treatment, 9(3), 197206. https://doi.org/10.1037/per0000289

Leary, T. (1957). Interpersonal diagnosis of personality; a functional theory and methodology for personality evaluation. Ronald Press.

Levy, K. N., Kivity, Y., Johnson, B. N. \& Gooch, C. V. (2018). Adult attachment as a predictor and moderator of psychotherapy outcome: A meta-analysis. Journal of Clinical Psychology, 74(11), 1996-2013. https://doi.org/10.1002/jclp.22685 
Mallinckrodt, B. (2010). The psychotherapy relationship as attachment: Evidence and implications. Journal of Social and Personal Relationships, 27(2), 262-270. https://doi.org/10.1177/0265407509360905

Mikulincer, M. \& Shaver, P. R. (2003). The Attachment Behavioral System In Adulthood: Activation, Psychodynamics, And Interpersonal Processes. Advances in Experimental Social Psychology, 53-152. https://doi.org/10.1016/s0065-2601(03)01002-5

Muthén, L.K. and Muthén, B.O. (2019). Mplus User's Guide (2019). Eighth Edition. Los Angeles, CA: Muthén \& Muthén

MetricWire Inc. (2019). MetricWire (Version 4.2.8) [Mobile application software]. https://metricwire.com/

Overall, N. C., Fletcher, G. J. O. \& Friesen, M. D. (2003). Mapping the Intimate Relationship Mind: Comparisons between Three Models of Attachment Representations. Personality and Social Psychology Bulletin, 29(12), 1479-1493. https://doi.org/10.1177/0146167203251519

Pierce, T. \& Lydon, J. E. (2001). Global and specific relational models in the experience of social interactions. Journal of Personality and Social Psychology, 80(4), 613-631. https://doi.org/10.1037/0022-3514.80.4.613

Revelle, W. (2020). psych: Procedures for Personality and Psychological Research (Version 2.0.7) [R package]. Northwestern University.

Shaver, P. R. \& Mikulincer, M. (2010). New directions in attachment theory and research. Journal of Social and Personal Relationships, 27(2), 163-172. https://doi.org/10.1177/0265407509360899

Sadikaj, G., Moskowitz, D. S., Russell, J. J., Zuroff, D. C. \& Paris, J. (2013). Quarrelsome behavior in borderline personality disorder: Influence of behavioral and affective reactivity to perceptions of others. Journal of Abnormal Psychology, 122(1), 195-207. https://doi.org/10.1037/a0030871 
Sadikaj, G., Moskowitz, D. S. \& Zuroff, D. C. (2011). Attachment-related affective dynamics: Differential reactivity to others' interpersonal behavior. Journal of Personality and Social Psychology, 100(5), 905-917. https://doi.org/10.1037/a0022875

Sadikaj, G., Wright, A.G.C., Dunkley, D., Zuroff, D. \& Moskowitz, D.S. (2021). Multilevel structural equation modeling for intensive longitudinal data: A practical guide for personality researchers. In J.F. Rauthmann (Ed.) Handbook of Personality Dynamics and Processes (pp. 856-887). Elsevier.

Schönbrodt, F. D., \& Perugini, M. (2013). At what sample size do correlations stabilize?. Journal of Research in Personality, 47(5), 609-612.

Schreiber, A. M., Pilkonis, P. A., \& Hallquist, M. N. (2021). Dispositional attachment style moderates the effects of physiological coregulation on short-term changes in attachment anxiety and avoidance. Personality Disorders: Theory, Research, and Treatment. Advance online publication. https://doi.org/10.1037/per0000472

Smith, A. E., Msetfi, R. M. \& Golding, L. (2010). Client self-rated adult attachment patterns and the therapeutic alliance: A systematic review. Clinical Psychology Review, 30(3), 326-337. https://doi.org/10.1016/j.cpr.2009.12.007

Tasca, G. A. \& Balfour, L. (2014). Attachment and eating disorders: A review of current research. International Journal of Eating Disorders, 47(7), 710-717. https://doi.org/10.1002/eat.22302

Vandevivere, E., Bosmans, G., Roels, S., Dujardin, A. \& Braet, C. (2018). State Trust in Middle Childhood: An Experimental Manipulation of Maternal Support. Journal of Child and Family Studies, 27(4), 1252-1263. https://doi.org/10.1007/s10826-017-0954-7

Vazire, S. (2010). Who knows what about a person? The self-other knowledge asymmetry (SOKA) model. Journal of Personality and Social Psychology, 98(2), 281-300. https://doi.org/10.1037/a0017908 
Verhees, M. W., Ceulemans, E., van IJzendoorn, M. H., Bakermans-Kranenburg, M. J., \& Bosmans, G. (2020). State attachment variability across distressing situations in middle childhood. Social Development, 29(1), 196-216.

Watson, D., Clark, L. A. \& Tellegen, A. (1988). Development and validation of brief measures of positive and negative affect: The PANAS scales. Journal of Personality and Social Psychology, 54(6), 1063-1070. https://doi.org/10.1037/0022-3514.54.6.1063

Wiggins, J. S. (1991). Agency and communion as conceptual coordinates for the understanding and measurement of interpersonal behavior. In D. Cicchetti \& W. M. Grove (Eds.), Thinking clearly about psychology: Essays in honor of Paul E. Meehl, Vol. 1. Matters of public interest; Vol. 2. Personality and psychopathology (pp. 89113). University of Minnesota Press.

Woods, W. C., Arizmendi, C., Gates, K. M., Stepp, S. D., Pilkonis, P. A. \& Wright, A. G. C. (2020). Personalized models of psychopathology as contextualized dynamic processes: An example from individuals with borderline personality disorder. Journal of Consulting and Clinical Psychology, 88(3), 240-254. https://doi.org/10.1037/ccp0000472

Wright, A. G., Pincus, A., \& Hopwood, C. J. (2020). Contemporary Integrative Interpersonal Theory: Integrating Structure, Dynamics, Temporal Scale, and Levels of Analysis. https://doi.org/10.31234/osf.io/fknc8

Wright, A. G. C., Stepp, S. D., Scott, L. N., Hallquist, M. N., Beeney, J. E., Lazarus, S. A. \& Pilkonis, P. A. (2017). The effect of pathological narcissism on interpersonal and affective processes in social interactions. Journal of Abnormal Psychology, 126(7), 898-910. https://doi.org/10.1037/abn0000286 
765 Zhang, F. (2009). The relationship between state attachment security and daily interpersonal experience. Journal of Research in Personality, 43(3), 511-515. https://doi.org/10.1016/j.jrp.2008.12.026

768 Zimmermann, J. \& Wright, A.G.C. (2017). Beyond description in interpersonal construct validation: Methodological advances in the circumplex structural summary approach. Assessment, 24(1), 3-23.

771 Zinbarg, R.E., Revelle, W., Yovel, I., \& Li, W. (2005). Cronbach' $\alpha$, Revelle's $\beta$, and McDonald's $\omega$ : Their relations with each other and two alternative conceptualizations of reliability. Psychometrika, 70(1), 123-133. 


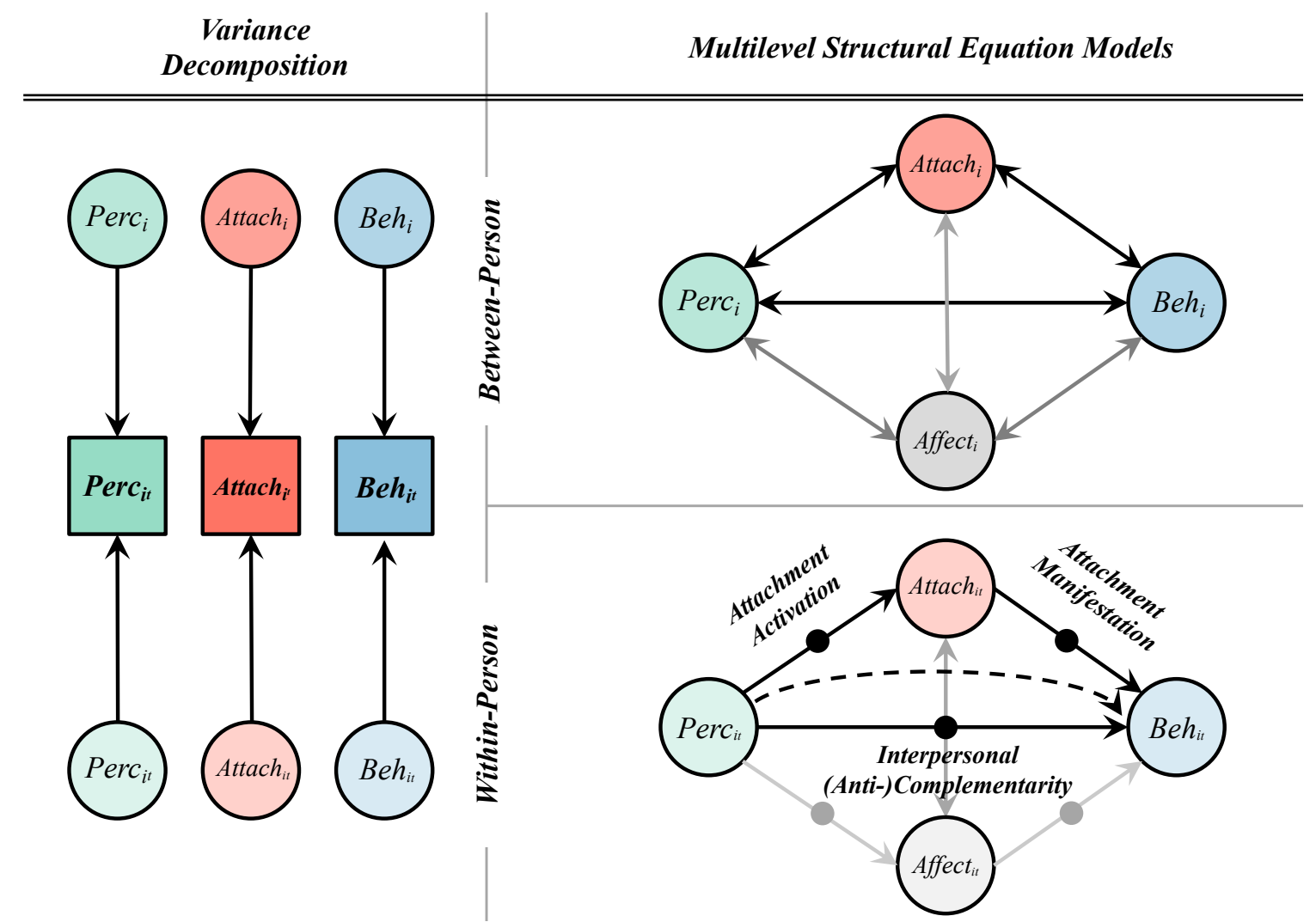

Figure 1. Schematic overview of estimated multilevel structural equation models. The panel on the left depicts the latent decomposition of observed momentary variables into between- (subscript $i$ ) and within-person (subscript $i t$ ) variance. The right panel depicts the within-person (bottom) and betweenperson (top) portion of our focal model. Grey paths denote sensitivity analyses as presented in Tables 3-5. Solid dots represent random slopes on within-person regression paths. Perc $=$ perceived affiliation or dominance; Beh = own affiliative or dominant behavior; Attach = attachment. Parameters not reported in the tables (e.g., residual variances, covariates) are not depicted in diagrams, but respective Mplus code providing full models specification can be found online at: https://osf.io/3vy4m/. 
Table 1

785 Correlations among study variables at within and between-person levels.

\begin{tabular}{|c|c|c|c|c|c|c|c|c|c|c|}
\hline & $\begin{array}{c}1 \\
\text { secure }\end{array}$ & $\begin{array}{c}\mathbf{2} \\
\text { anxious }\end{array}$ & $\begin{array}{c}\mathbf{3} \\
\text { avoidant }\end{array}$ & $\begin{array}{c}\mathbf{4} \\
\text { perceived } \\
\text { warmth }\end{array}$ & $\begin{array}{c}\mathbf{5} \\
\text { perceived } \\
\text { dominance }\end{array}$ & $\begin{array}{c}\mathbf{6} \\
\text { warmth }\end{array}$ & $\begin{array}{c}7 \\
\text { dominance }\end{array}$ & $\begin{array}{c}\mathbf{8} \\
\text { positive } \\
\text { affect }\end{array}$ & $\begin{array}{c}9 \\
\text { negative } \\
\text { affect }\end{array}$ & $\begin{array}{c}10 \\
\text { closeness }\end{array}$ \\
\hline 1 & 1 & .15 & -.30 & .65 & -.09 & .69 & .06 & .55 & -.21 & .77 \\
\hline 2 & .37 & 1 & .67 & -.16 & .04 & -.18 & -.00 & .12 & .53 & .02 \\
\hline 3 & -.44 & .02 & 1 & -.50 & .12 & -.50 & .01 & -.09 & .76 & -.33 \\
\hline 4 & .54 & .13 & -.35 & 1 & -.02 & .90 & -.03 & .38 & -.49 & .49 \\
\hline 5 & -.12 & .02 & .11 & -.21 & 1 & -.14 & .60 & -.11 & .02 & -.10 \\
\hline 6 & .48 & .12 & -.37 & .61 & -.18 & 1 & -.03 & .50 & -.45 & .53 \\
\hline 7 & .07 & .03 & -.02 & -.07 & -.31 & -.04 & 1 & .03 & -.06 & .00 \\
\hline 8 & .52 & .17 & -.34 & .54 & -.14 & .57 & .04 & 1 & -.09 & .39 \\
\hline 9 & -.31 & .11 & .41 & -.45 & .21 & -.45 & .04 & -.53 & 1 & -.15 \\
\hline 10 & .69 & .36 & -.28 & .27 & -.05 & .27 & .13 & .30 & -.12 & 1 \\
\hline$M$ & 2.49 & 1.15 & 0.69 & 73.90 & 50.02 & 74.25 & 45.51 & 54.87 & 17.71 & 67.43 \\
\hline$S D$ & 1.18 & 1.12 & 0.93 & 21.16 & 20.66 & 20.74 & 19.82 & 24.87 & 17.60 & 30.42 \\
\hline$I C C$ & .17 & .43 & .31 & .18 & .16 & .21 & .16 & .20 & .34 & .12 \\
\hline
\end{tabular}

786 Note. $N_{\text {between }}=263 ; N_{\text {within }}=3971$; values below diagonal represent within-person coefficients and values above diagonal represent between-person

787 coefficients. Values in bold are those for which the credibility interval did not contain zero. 
Table 2

Standardized Key Coefficients From Focal Multilevel Models.

\begin{tabular}{|c|c|c|}
\hline & Affiliation & Dominance \\
\hline & $\beta[95 \% \mathrm{CIs}]$ & $\beta[95 \%$ CIs $]$ \\
\hline \multicolumn{3}{|l|}{ anxiety } \\
\hline \multicolumn{3}{|l|}{ between-person } \\
\hline Beh $_{i} \leftrightarrow$ Perc $_{i}$ & $.90[.85 ; .93]$ & $.55[.38 ; .67]$ \\
\hline Perc $_{i} \leftrightarrow$ Attachment $_{i}$ & $-.18[-.35 ;-.04]$ & $.03[-.15 ; .20]$ \\
\hline Attachment $_{i} \leftrightarrow$ Beh $_{\mathrm{i}}$ & $-.20[-.35 ;-.07]$ & $-.01[-.16 ; .16]$ \\
\hline \multicolumn{3}{|l|}{ within-person } \\
\hline interp. complementarity (c) & $.61[.58 ; .63]$ & $-.28[-.32 ;-.25]$ \\
\hline attachment activation (a) & $.13[.09 ; .17]$ & $.00[-.03 ; .04]$ \\
\hline attachment manifestation (b) & $.02[-.02 ; .05]$ & $.02[-.02 ; .05]$ \\
\hline \multicolumn{3}{|l|}{ avoidance } \\
\hline \multicolumn{3}{|l|}{ between-person } \\
\hline Beh $_{\mathrm{i}} \leftrightarrow$ Perc $_{\mathrm{i}}$ & $.90[.86 ; .93]$ & $.58[.42 ; .70]$ \\
\hline $\operatorname{Perc}_{i} \leftrightarrow$ Attachment $_{i}$ & $-.54[-.65 ;-.41]$ & $.09[-.09 ; .24]$ \\
\hline Attachment $_{i} \leftrightarrow$ Beh $_{i}$ & $-.52[-.63 ;-.39]$ & $-.04[-.19 ; .15]$ \\
\hline \multicolumn{3}{|l|}{ within-person } \\
\hline interp. complementarity (c) & $.56[.53 ; .59]$ & $-.28[-.32 ;-.25]$ \\
\hline attachment activation (a) & $-.28[-.32 ;-.24]$ & $.09[.06 ; .13]$ \\
\hline attachment manifestation (b) & $-.19[-.23 ;-.06]$ & $-.03[-.06 ; .01]$ \\
\hline \multicolumn{3}{|l|}{ security } \\
\hline \multicolumn{3}{|l|}{ between-person } \\
\hline Beh $_{\mathrm{i}} \leftrightarrow$ Perc $_{\mathrm{i}}$ & $.90[.86 ; .94]$ & $.55[.39 ; .73]$ \\
\hline Perc $_{i} \leftrightarrow$ Attachment $_{i}$ & $.66[.57 ; .76]$ & $.12[-.08 ; .29]$ \\
\hline Attachment $_{\mathrm{i}} \leftrightarrow$ Beh $_{\mathrm{i}}$ & $.67[.58 ; .75]$ & $-.05[-.24 ; .14]$ \\
\hline \multicolumn{3}{|l|}{ within-person } \\
\hline interp. complementarity (c) & $.52[.48 ; .56]$ & $-.28[-.31 ;-.24]$ \\
\hline attachment activation (a) & $.49[.45 ; .52]$ & $.07[.04 ; .11]$ \\
\hline attachment manifestation (b) & $.19[.07 ; .23]$ & $-.06[-.10 ;-.01]$ \\
\hline
\end{tabular}


Table 3

794 Standardized Key Coefficients From Sensitivity Analyses controlling for Negative Affect.

\begin{tabular}{|c|c|c|}
\hline & Affiliation & Dominance \\
\hline & $\beta[95 \% \mathrm{CIs}]$ & $\beta[95 \% \mathrm{CIs}]$ \\
\hline \multicolumn{3}{|l|}{ anxiety } \\
\hline \multicolumn{3}{|l|}{ between-person } \\
\hline $\mathrm{Beh}_{\mathrm{i}} \leftrightarrow \operatorname{Perc}_{\mathrm{i}}$ & $.87[.79 ; .91]$ & $.38[.17 ; .55]$ \\
\hline Perc $_{i} \leftrightarrow$ Attachment $_{i}$ & $-.27[-.42 ;-.11]$ & $-.05[-.23 ; .11]$ \\
\hline Attachment $_{\mathrm{i}} \leftrightarrow$ Beh $_{\mathrm{i}}$ & $-.24[-.41 ;-.07]$ & $-.03[-.19 ; .14]$ \\
\hline $\mathrm{NA}_{\mathrm{i}} \leftrightarrow \mathrm{Beh}_{\mathrm{i}}$ & $-.50[-.61 ;-.36]$ & $-.16[-.32 ; .00]$ \\
\hline $\operatorname{Perc}_{i} \leftrightarrow \mathrm{NA}_{i}$ & $-.46[-.57 ;-.32]$ & $-.25[-.42 ;-.09]$ \\
\hline Attachment $_{i} \leftrightarrow \mathrm{NA}_{\mathrm{i}}$ & $.55[.42 ; .66]$ & $.51[.39 ; .61]$ \\
\hline \multicolumn{3}{|l|}{ within-person } \\
\hline interp. complementarity (c) & $.64[.61 ; .66]$ & $-.28[-.31 ;-.25]$ \\
\hline attachment activation (a) & $.16[.11 ; .20]$ & $.03[-.01 ; .07]$ \\
\hline attachment manifestation (b) & $.20[.10 ; .24]$ & $-.01[-.06 ; .03]$ \\
\hline $\mathrm{NA}_{\mathrm{it}} \rightarrow \mathrm{Beh}_{\mathrm{it}}$ & $-.45[-.48 ;-.42]$ & $.20[.16 ; .24]$ \\
\hline $\operatorname{Perc}_{i t} \rightarrow \mathrm{NA}_{\mathrm{it}}$ & $-.46[-.50 ;-.43]$ & $.04[.00 ; .08]$ \\
\hline Attachment $_{i t} \leftrightarrow \mathrm{NA}_{\mathrm{it}}$ & $.17[.14 ; .21]$ & $.11[.08 ; .14]$ \\
\hline \multicolumn{3}{|l|}{ avoidance } \\
\hline \multicolumn{3}{|l|}{ between-person } \\
\hline Beh $_{i} \leftrightarrow$ Perc $_{i}$ & $.87[.82 ; .92]$ & $.42[.18 ; .59]$ \\
\hline $\operatorname{Perc}_{i} \leftrightarrow$ Attachment $_{i}$ & $-.52[-.63 ;-.38]$ & $-.13[-.29 ; .04]$ \\
\hline Attachment $_{i} \leftrightarrow$ Beh $_{i}$ & $-.50[-.63 ;-.38]$ & $.01[-.17 ; .18]$ \\
\hline $\mathrm{NA}_{\mathrm{i}} \leftrightarrow \mathrm{Beh}_{\mathrm{i}}$ & $-.53[-.64 ;-.39]$ & $-.16[-.32 ; .02]$ \\
\hline $\operatorname{Perc}_{i} \leftrightarrow \mathrm{NA}_{i}$ & $-.49[-.61 ;-.36]$ & $-.26[-.42 ;-.09]$ \\
\hline Attachment $_{i} \leftrightarrow \mathrm{NA}_{\mathrm{i}}$ & $.75[.67 ; .82]$ & $.72[.64 ; .79]$ \\
\hline \multicolumn{3}{|l|}{ within-person } \\
\hline interp. complementarity (c) & $.64[.61 ; .67]$ & $-.28[-.32 ;-.24]$ \\
\hline attachment activation (a) & $-.37[-.41 ;-.33]$ & $-.03[-.07 ; .01]$ \\
\hline attachment manifestation (b) & $-.23[-.27 ;-.09]$ & $.03[-.02 ; .07]$ \\
\hline $\mathrm{NA}_{\mathrm{it}} \rightarrow \mathrm{Beh}_{\mathrm{it}}$ & $-.35[-.39 ;-.32]$ & $.18[.14 ; .22]$ \\
\hline Perc $_{i t} \rightarrow \mathrm{NA}_{i t}$ & $-.48[-.51 ;-.44]$ & $.04[.00 ; .07]$ \\
\hline Attachment $_{i t} \leftrightarrow \mathrm{NA}_{\mathrm{it}}$ & $.28[.25 ; .31]$ & $.41[.38 ; .43]$ \\
\hline \multicolumn{3}{|l|}{ security } \\
\hline \multicolumn{3}{|l|}{ between-person } \\
\hline Beh $_{i} \leftrightarrow$ Perc $_{i}$ & $.85[.76 ; .89]$ & $.40[.21 ; .59]$ \\
\hline Perc $_{i} \leftrightarrow$ Attachment $_{i}$ & $.57[.41 ; .68]$ & $.15[-.05 ; .33]$ \\
\hline Attachment $_{i} \leftrightarrow$ Beh $_{i}$ & $.55[.34 ; .65]$ & $.01[-.18 ; .21]$ \\
\hline $\mathrm{NA}_{\mathrm{i}} \leftrightarrow \mathrm{Beh}_{\mathrm{i}}$ & $-.52[-.64 ;-.37]$ & $-.13[-.31 ; .04]$ \\
\hline
\end{tabular}




\begin{tabular}{|c|c|c|}
\hline $\operatorname{Perc}_{i} \leftrightarrow \mathrm{NA}_{i}$ & $-.46[-.61 ;-.35]$ & $-.27[-.42 ;-.11]$ \\
\hline Attachment $_{\mathrm{i}} \leftrightarrow \mathrm{NA}_{\mathrm{i}}$ & $-.21[-.38 ;-.01]$ & $-.28[-.42 ;-.13]$ \\
\hline \multicolumn{3}{|l|}{ within-person } \\
\hline interp. complementarity (c) & $.64[.61 ; .67]$ & $-.28[-.32 ;-.25]$ \\
\hline attachment activation (a) & $.51[.47 ; .54]$ & $.07[.03 ; .11]$ \\
\hline attachment manifestation (b) & $.43[.14 ; .46]$ & $-.04[-.08 ;-.00]$ \\
\hline $\mathrm{NA}_{i t} \rightarrow \mathrm{Beh}_{\mathrm{it}}$ & $-.29[-.34 ;-.26]$ & $.18[.14 ; .22]$ \\
\hline $\operatorname{Perc}_{i t} \rightarrow \mathrm{NA}_{\mathrm{it}}$ & $-.51[-.54 ;-.44]$ & $.04[-.00 ; .08]$ \\
\hline Attachment $_{i t} \leftrightarrow \mathrm{NA}_{i t}$ & $-.14[-.17 ;-.10]$ & $-.31[-.34 ;-.28]$ \\
\hline
\end{tabular}

795 Note. $N_{\text {between }}=263 ; N_{\text {within }}=3971 ;$ Perc $=$ perceived affiliation or dominance; $\mathrm{Beh}=\mathrm{own}$ affiliative or 796 dominant behavior; NA = negative affect; Values in bold are those for which the credibility interval did 797 not contain zero. 
Table 4

Standardized Key Coefficients From Sensitivity Analyses controlling for Positive Affect.

\begin{tabular}{|c|c|c|}
\hline & Affiliation & Dominance \\
\hline & $\beta[95 \% \mathrm{CIs}]$ & $\beta[95 \% \mathrm{CIs}]$ \\
\hline \multicolumn{3}{|l|}{ anxiety } \\
\hline \multicolumn{3}{|l|}{ between-person } \\
\hline Beh $_{i} \leftrightarrow$ Perc $_{i}$ & $.87[.79 ; .91]$ & $.51[.27 ; .67]$ \\
\hline $\operatorname{Perc}_{i} \leftrightarrow$ Attachment $_{i}$ & $-.26[-.42 ;-.11]$ & $-.01[-.18 ; .15]$ \\
\hline Attachment $_{\mathrm{i}} \leftrightarrow$ Beh $_{\mathrm{i}}$ & $-.23[-.38 ;-.06]$ & $.00[-.16 ; .17]$ \\
\hline $\mathrm{PA}_{\mathrm{i}} \leftrightarrow \mathrm{Beh}_{\mathrm{i}}$ & $.22[.02 ; .37]$ & $-.04[-.20 ; .12]$ \\
\hline $\operatorname{Perc}_{i} \leftrightarrow$ PA $_{i}$ & $.38[.20 ; .51]$ & $.11[-.06 ; .26]$ \\
\hline Attachment $_{i} \leftrightarrow \mathrm{PA}_{\mathrm{i}}$ & $.08[-.11 ; .23]$ & $.13[-.03 ; .27]$ \\
\hline \multicolumn{3}{|l|}{ within-person } \\
\hline interp. complementarity (c) & $.63[.60 ; .66]$ & $-.29[-.32 ;-.25]$ \\
\hline attachment activation (a) & $.15[.10 ; .20]$ & $.02[-.02 ; .06]$ \\
\hline attachment manifestation (b) & $.04[.01 ; .07]$ & $.03[-.01 ; .07]$ \\
\hline $\mathrm{PA}_{\text {it }} \rightarrow \mathrm{Beh}_{\mathrm{it}}$ & $.54[.51 ; .57]$ & $-.13[-.16 ;-.09]$ \\
\hline $\operatorname{Perc}_{i t} \rightarrow \mathrm{PA}_{i t}$ & $.60[.57 ; .62]$ & $.04[.01 ; .08]$ \\
\hline Attachment $_{i t} \leftrightarrow \mathrm{PA}_{\text {it }}$ & $.13[.10 ; .16]$ & $.16[.13 ; .19]$ \\
\hline \multicolumn{3}{|l|}{ avoidance } \\
\hline \multicolumn{3}{|l|}{ between-person } \\
\hline Beh $_{\mathrm{i}} \leftrightarrow$ Perc $_{\mathrm{i}}$ & $.86[.79 ; .91]$ & $.52[.29 ; .67]$ \\
\hline Perc $_{i} \leftrightarrow$ Attachment $_{i}$ & $-.54[-.66 ;-.40]$ & $-.09[-.25 ; .10]$ \\
\hline Attachment $_{\mathrm{i}} \leftrightarrow$ Beh $_{\mathrm{i}}$ & $-.54[-.67 ;-.39]$ & $.04[-.12 ; .20]$ \\
\hline $\mathrm{PA}_{\mathrm{i}} \leftrightarrow \mathrm{Beh}_{\mathrm{i}}$ & $.24[.06 ; .42]$ & $-.04[-.23 ; .15]$ \\
\hline $\operatorname{Perc}_{\mathrm{i}} \leftrightarrow \mathrm{PA}_{\mathrm{i}}$ & $.40[.21 ; .56]$ & $.09[-.09 ; .26]$ \\
\hline Attachment $_{i} \leftrightarrow$ PA $_{i}$ & $-.07[-.26 ; .11]$ & $-.11[-.27 ; .07]$ \\
\hline \multicolumn{3}{|l|}{ within-person } \\
\hline interp. complementarity (c) & $.64[.61 ; .66]$ & $-.29[-.32 ;-.25]$ \\
\hline attachment activation (a) & $-.38[-.42 ;-.33]$ & $-.04[-.07 ; .01]$ \\
\hline attachment manifestation (b) & $-.21[-.24 ;-.10]$ & $.06[.01 ; .10]$ \\
\hline $\mathrm{PA}_{\mathrm{it}} \rightarrow \mathrm{Beh}_{\mathrm{it}}$ & $.48[.44 ; .51]$ & $-.10[-.14 ;-.06]$ \\
\hline $\operatorname{Perc}_{i t} \rightarrow \mathrm{PA}_{i t}$ & $.62[.59 ; .64]$ & $.04[.00 ; .07]$ \\
\hline Attachment $_{i t} \leftrightarrow \mathrm{PA}_{i t}$ & $-.16[-.19 ;-.13]$ & $-.35[-.38 ;-.32]$ \\
\hline \multicolumn{3}{|l|}{ security } \\
\hline \multicolumn{3}{|l|}{ between-person } \\
\hline Beh $_{\mathrm{i}} \leftrightarrow$ Perc $_{\mathrm{i}}$ & $.85[.79 ; .90]$ & $.49[.28 ; .68]$ \\
\hline Perc $_{i} \leftrightarrow$ Attachment $_{i}$ & $.58[.45 ; .69]$ & $.15[-.03 ; .31]$ \\
\hline Attachment $_{\mathrm{i}} \leftrightarrow$ Beh $_{\mathrm{i}}$ & $.54[.40 ; .66]$ & $.02[-.16 ; .19]$ \\
\hline $\mathrm{PA}_{\mathrm{i}} \leftrightarrow \mathrm{Beh}_{\mathrm{i}}$ & $.25[.05 ; .41]$ & $-.03[-.21 ; .16]$ \\
\hline
\end{tabular}




\begin{tabular}{|c|c|c|}
\hline $\operatorname{Perc}_{i} \leftrightarrow \mathrm{PA}_{i}$ & $.40[.23 ; .54]$ & $.11[-.06 ; .26]$ \\
\hline Attachment $_{i} \leftrightarrow \mathrm{PA}_{\mathrm{i}}$ & $.47[.30 ; .60]$ & $.57[.46 ; .68]$ \\
\hline \multicolumn{3}{|l|}{ within-person } \\
\hline interp. complementarity (c) & $.64[.61 ; .66]$ & $-.28[-.32 ;-.25]$ \\
\hline attachment activation (a) & $.51[.48 ; .54]$ & $.07[.03 ; .11]$ \\
\hline attachment manifestation (b) & $.34[.31 ; .38]$ & $-.05[-.09 ;-.00]$ \\
\hline $\mathrm{PA}_{\mathrm{it}} \rightarrow \mathrm{Beh}_{\mathrm{it}}$ & $.36[.32 ; .40]$ & $-.10[-.14 ;-.06]$ \\
\hline $\operatorname{Perc}_{i t} \rightarrow \mathrm{PA}_{i t}$ & $.62[.60 ; .65]$ & $.05[.01 ; .08]$ \\
\hline Attachment $_{i t} \leftrightarrow$ PA $_{i t}$ & $.33[.30 ; .36]$ & $.51[.48 ; .53]$ \\
\hline
\end{tabular}

$800 \quad$ Note. $N_{\text {between }}=263 ; N_{\text {within }}=3971 ;$ Perc $=$ perceived affiliation or dominance; $\mathrm{Beh}=$ own affiliative or 801 dominant behavior; $\mathrm{PA}=$ positive affect; Values in bold are those for which the credibility interval did not 802 contain zero. 
Table 5

804 Standardized Key Coefficients From Sensitivity Analyses controlling for Closeness of the 805 Relationship.

\begin{tabular}{|c|c|c|}
\hline & Affiliation & Dominance \\
\hline & $\beta[95 \% \mathrm{CIs}]$ & $\beta[95 \% \mathrm{CIs}]$ \\
\hline \multicolumn{3}{|l|}{ anxiety } \\
\hline \multicolumn{3}{|l|}{ between-person } \\
\hline $\mathrm{Beh}_{\mathrm{i}} \leftrightarrow \operatorname{Perc}_{\mathrm{i}}$ & $.88[.82 ; .92]$ & $.48[.30 ; .63]$ \\
\hline $\operatorname{Perc}_{i} \leftrightarrow$ Attachment $_{i}$ & $-.26[-.41 ;-.08]$ & $-.06[-.22 ; .12]$ \\
\hline Attachment $_{i} \leftrightarrow$ Beh $_{i}$ & $-.23[-.40 ;-.07]$ & $-.04[-.20 ; .12]$ \\
\hline Closeness $_{\mathrm{i}} \leftrightarrow$ Beh $_{\mathrm{i}}$ & $.39[.18 ; .53]$ & $-.03[-.22 ; .14]$ \\
\hline Perc $_{i} \leftrightarrow$ Closeness $_{i}$ & $.43[.22 ; .57]$ & $.08[-.11 ; .26]$ \\
\hline Attachment $_{i} \leftrightarrow$ Closeness $_{i}$ & $-.03[-.24 ; .15]$ & $.03[-.16 ; .19]$ \\
\hline \multicolumn{3}{|l|}{ within-person } \\
\hline interp. complementarity (c) & $.63[.60 ; .65]$ & $-.29[-.32 ;-.26]$ \\
\hline attachment activation (a) & $.14[.09 ; .18]$ & $.02[-.02 ; .06]$ \\
\hline attachment manifestation (b) & $.06[.02 ; .10]$ & $.04[-.00 ; .08]$ \\
\hline Closenessit $_{i t} \rightarrow$ Beh $_{\text {it }}$ & $.25[.21 ; .28]$ & $-.06[-.10 ;-.02]$ \\
\hline Perc $_{i t} \rightarrow$ Closeness $_{i t}$ & $.31[.27 ; .34]$ & $.12[.09 ; .16]$ \\
\hline Attachment $_{\text {it }} \leftrightarrow$ Closeness $_{i t}$ & $.33[.30 ; .36]$ & $.34[.31 ; .37]$ \\
\hline \multicolumn{3}{|l|}{ avoidance } \\
\hline \multicolumn{3}{|l|}{ between-person } \\
\hline $\operatorname{Beh}_{i} \leftrightarrow$ Perc $_{i}$ & $.87[.80 ; .92]$ & $.46[.28 ; .63]$ \\
\hline $\operatorname{Perc}_{i} \leftrightarrow$ Attachment $_{i}$ & $-.54[-.65 ;-.39]$ & $-.12[-.27 ; .02]$ \\
\hline Attachment $_{i} \leftrightarrow$ Beh $_{i}$ & $-.52[-.65 ;-.38]$ & $.01[-.16 ; .17]$ \\
\hline Closeness $_{\mathrm{i}} \leftrightarrow$ Beh $_{\mathrm{i}}$ & $.40[.21 ; .56]$ & $-.05[-.21 ; .14]$ \\
\hline Perc $_{i} \leftrightarrow$ Closeness $_{i}$ & $.43[.24 ; .58]$ & $.09[-.08 ; .29]$ \\
\hline Attachment $_{i} \leftrightarrow$ Closeness $_{i}$ & $-.41[-.55 ;-.21]$ & $-.35[-.48 ;-.21]$ \\
\hline \multicolumn{3}{|l|}{ within-person } \\
\hline interp. complementarity (c) & $.64[.61 ; .66]$ & $-.28[-.32 ;-.25]$ \\
\hline attachment activation (a) & $-.36[-.39 ;-.31]$ & $-.04[-.08 ; .01]$ \\
\hline attachment manifestation (b) & $-.32[-.36 ;-.11]$ & $.11[.03 ; .16]$ \\
\hline Closenessit $_{i} \rightarrow$ Beh $_{\text {it }}$ & $.18[.15 ; .24]$ & $-.02[-.05 ; .02]$ \\
\hline Perc $_{\text {it }} \rightarrow$ Closeness it & $.33[.29 ; .37]$ & $.12[.09 ; .16]$ \\
\hline Attachment $_{\text {it }} \leftrightarrow$ Closeness $_{\text {it }}$ & $-.21[-.24 ;-.18]$ & $-.29[-.32 ;-.26]$ \\
\hline \multicolumn{3}{|l|}{ security } \\
\hline \multicolumn{3}{|l|}{ between-person } \\
\hline $\mathrm{Beh}_{\mathrm{i}} \leftrightarrow \operatorname{Perc}_{\mathrm{i}}$ & $.86[.80 ; .91]$ & $.52[.31 ; .67]$ \\
\hline Perc $_{i} \leftrightarrow$ Attachment $_{i}$ & $.60[.46 ; .70]$ & $.15[-.03 ; .30]$ \\
\hline Attachment $_{i} \leftrightarrow$ Beh $_{i}$ & $.55[.42 ; .67]$ & $-.01[-.19 ; .17]$ \\
\hline
\end{tabular}




\begin{tabular}{|c|c|c|}
\hline Closeness $_{\mathrm{i}} \leftrightarrow$ Beh $_{\mathrm{i}}$ & $.39[.23 ; .52]$ & $-.05[-.23 ; .13]$ \\
\hline Perc $_{i} \leftrightarrow$ Closeness $_{i}$ & $.44[.27 ; .56]$ & $.08[-.11 ; .25]$ \\
\hline Attachment $_{\mathrm{i}} \leftrightarrow$ Closeness $_{\mathrm{i}}$ & $.72[.61 ; .81]$ & $.76[.66 ; .83]$ \\
\hline \multicolumn{3}{|l|}{ within-person } \\
\hline interp. complementarity (c) & $.64[.59 ; .66]$ & $-.28[-.32 ;-.25]$ \\
\hline attachment activation (a) & $.50[.46 ; .53]$ & $.07[.03 ; .10]$ \\
\hline attachment manifestation (b) & $.65[.12 ; .69]$ & $-.13[-.18 ;-.05]$ \\
\hline Closeness $_{\text {it }} \rightarrow$ Beh $_{\text {it }}$ & $-.13[-.16 ; .20]$ & $.04[-.02 ; .09]$ \\
\hline Perc $_{i t} \rightarrow$ Closeness $_{i t}$ & $.35[.30 ; .39]$ & $.12[.08 ; .16]$ \\
\hline Attachment $_{i t} \leftrightarrow$ Closeness $_{i t}$ & $.65[.64 ; .67]$ & $.68[.66 ; .70]$ \\
\hline
\end{tabular}

806 Note. $N_{\text {between }}=263 ; N_{\text {within }}=3971 ;$ Perc $=$ perceived affiliation or dominance; Beh $=$ own affiliative or

807 dominant behavior; Values in bold are those for which the credibility interval did not contain zero. 